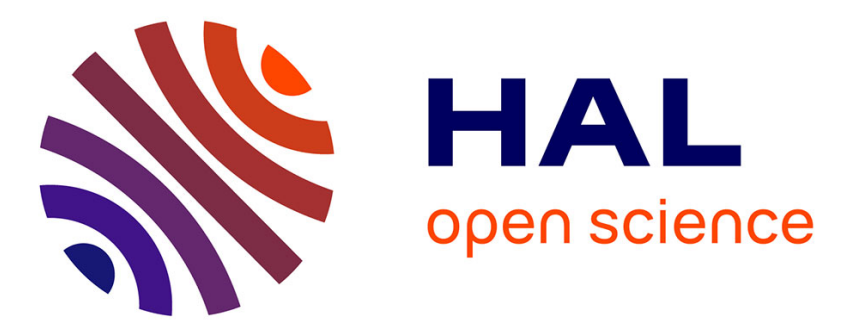

\title{
Random monitoring in financing relationships
}

Hind Sami

\section{- To cite this version:}

Hind Sami. Random monitoring in financing relationships. Quarterly Review of Economics and Finance, 2009, 49, pp.239-252. 10.1016/j.qref.2007.09.009 . halshs-00522629

\section{HAL Id: halshs-00522629 \\ https://shs.hal.science/halshs-00522629}

Submitted on 1 Oct 2010

HAL is a multi-disciplinary open access archive for the deposit and dissemination of scientific research documents, whether they are published or not. The documents may come from teaching and research institutions in France or abroad, or from public or private research centers.
L'archive ouverte pluridisciplinaire HAL, est destinée au dépôt et à la diffusion de documents scientifiques de niveau recherche, publiés ou non, émanant des établissements d'enseignement et de recherche français ou étrangers, des laboratoires publics ou privés. 


\title{
Random Monitoring in Financing Relationships
}

\author{
Hind Sami *
}

April 2007

\begin{abstract}
This paper examines a financier's optimal monitoring intensity in a multiperiod financing relationship. We identify conditions under which the financier should sometimes misidentify the quality of an entrepreneur. Such an imperfect evaluation technology affects action choices by bad entrepreneurs. We first characterize the optimal monitoring intensity and show that it is one in which the investor monitors entrepreneurs randomly. Random monitoring in the first stage of a relationship induces bad entrepreneurs to reveal their intrinsic types. Second, because random monitoring reduces the share of bad entrepreneurs in the subsequent periods, we show that the financier can therefore realize substantial gains.
\end{abstract}

Keywords: Incentives - Monitoring - Screening.

JEL classification: D82, G30.

${ }^{*}$ Hind Sami is at IESEG School of Management (CNRS 8179). Address: 3 rue de la digue, 59000 Lille, h.sami@ieseg.fr. I would like to thank Franklin Allen, Christian At, Louis Eeckhoudt, David Musto, Denis Gromb, Rabia Nessah, Jean-Louis Rulliere, and especially Hadi Esfahani and Joseph Finnerty (co-editors) for their helpful comments and suggestions. The paper has also benefited very much from comments by two anonymous referees. All errors and shortcomings are solely my responsibility. 


\section{Introduction}

Standard agency theory tells us that optimal incentive schemes make use of all available information related to the agent's performance. Hart and Holmstrom (1987) motivate the fact that "agency relationships create a demand for monitoring". Principals have an incentive to monitor since it conveys information about the agent's behavior. Much of the literature on relationship financing argues that screening and monitoring can overcome information asymmetries and can provide firms with better incentives to perform in the interest of creditors. ${ }^{1}$ Yet, whenever monitoring is costly and/or the principal cannot observe an action that the agent is supposed to perform, the possibility of shirking by the agent arises (hidden action). ${ }^{2}$ This gives rise to the following question: what is the optimal nature of monitoring strategies, and how are these related to the length of relationships?

The answer to these questions seems rather clear. When more accurate appraisals of a firm's quality are costly, the optimal allocation of resources to evaluate firms will reflect investors' trade-offs between the marginal cost and the marginal benefit of more accurate appraisals. In this paper, we show that a financier may also consider how the probability that she misidentifies the quality of an entrepreneur affects entrepreneurs' behavior ex ante. We are interested particularly in finding general conditions under which random monitoring is optimal. We also aim to analyze whether the use of probation periods in relationship financing is beneficial to the principal. Our results should be relevant to the design of optimal verification strategies in relationship financing.

We develop a simple model of entrepreneurial finance and show that random monitoring by a financier during a probation period has two goals. The first goal is to identify which entrepreneurs are good and which ones are bad, so that bad firms can be liquidated. The selection of good entrepreneurs may involve a trial period in which financiers monitor in order to learn more about an entrepreneur's type and then decide whether to stop or continue the relationship. The usefulness of identifying entrepreneurs at the beginning of a relationship is particularly important

\footnotetext{
${ }^{1}$ Diamond (1984), and Fama (1985), among others, argue that banks have scale economies and comparative cost advantages over other lenders in producing information about the borrowers. Others, such as Chemmanur and Fulghieri (1994) attribute the monitoring ability of banks to their incentives to build their reputation as lenders. The literature on banks' incentives to monitor includes Winton (1993), Holmstrom and Tirole (1997) and Carletti (2004). See Boot (2000) for a more specific review of relationship banking.

${ }^{2}$ Costly state verification environment model was originally developed by Townsend (1979) and was subsequently extended by Diamond (1984), Gale and Hellwig (1985).
} 
if one recognizes that information about the firms' quality is asymmetric between entrepreneurs and creditors. In our setting, entrepreneurs may take hidden actions that affect expected period project revenues. In particular, some investments can be profitable hence, lowering the probability that the firm defaults on its loan obligations or suboptimal hence, increasing the likelihood of bankruptcy. ${ }^{3}$ Financiers are thus interested in discriminating between "intrinsically good" entrepreneurs, therefore make efficient investment decisions and firm value-maximizing decisions in all cases and opportunistic entrepreneurs who instead would persist with suboptimal projects if the probability of detection is sufficiently low and the cost of making value-increasing decisions is high. The second goal is to allow the financier to filter out bad entrepreneurs at a time when separation has low cost. Long-term relationships may become gradually costly over time if the contract tends to get richer as new information arises and to incorporate a growing number of contingent clauses over time -clauses specifying circumstances under which a party can make changes to the project or terminate it-.

We characterize the optimal monitoring intensity and show that it is one in which the investor investigates randomly. The general formulation is a dynamic principal agent costly state verification environment in which the agent's type is unknown and the principal and agent's interests are not aligned over action choice. In our relationship financing setting, the financier must choose the intensity of an evaluation technology to verify the entrepreneur's type, and the outcome of the evaluation affects whether the entrepreneur is retained after the probation period. We show that the investor optimally chooses a relatively small monitoring intensity in order to induce some of the bad entrepreneurs to reveal their intrinsic types.

We could have presented our analysis in the context of shareholders in a firm who must choose an evaluation technology to decide whether to replace management. Shareholders may want bad managers to take actions that signal that they should be replaced. ${ }^{4}$ Shareholders may optimally choose an imperfect evaluation technology as the possibility of misidentifying bad managers may provide the right incentives for management. So too, the analysis could have been posed in a venture capital/equity finance context. In that case, continued projects require additional capital, and the financier decides whether to refinance based on a noisy signal received about the entrepreneur's type.

\footnotetext{
${ }^{3}$ Fudenberg and Tirole (1995) show that managers' concerns about job security motivate them to prefer a smooth profile of earnings streams over time.

${ }^{4}$ The signal might be lower immediate revenues indicating that the manager is bad.
} 
Our paper relates to the literature on optimal monitoring initiated by Diamond (1984). By fulfilling the task of monitoring a firm's investment and type, a creditor can resolve the ambiguity of what has caused bad short-run results, and therefore allows implementing the efficient continuation decision. Potentially, this should eliminate the firm's moral hazard problem with respect to investment choice. In our setting the "hidden action" brings about the incentives problems and then we consider how random monitoring impacts corporate investment and financing decisions. ${ }^{5}$ This approach allows us to characterize how the probability of detection ultimately affects the ex ante behavior of managers.

The literature on strategic ignorance recasts the problem of screening an agent under asymmetric information (Carillo and Mariotti, 2000; Benabou and Tirole 2002). For example, Cremer (1995) and Dewatripont and Maskin (1995) argue that in a principal-agent problems, a credible commitment of a principal not to acquire information ex ante about the agent may strengthen incentives and overwhelm the gains from better information. ${ }^{6}$ Cowen and Glazer (1996) and Dubey and Wu (2001) show that a principal might benefit from having a less accurate picture of agents. One can interpret our paper as contributing to the literature on optimal monitoring by modeling the ex ante decisions of parties within a financing relationship environment. We explicitly model the features that characterize long-term financing relationships. First, the longer is the relationship the higher is the cost of terminating the contract. In our paper, the investor who finances the project at an early stage of the relationship acquires a good understanding of the environment through monitoring and can extract high future cash flows by threatening to liquidate the project. But once the probation has come to an end, because the financier cannot credibly threaten to liquidate the project, she can extract only a fraction of the cash flows generated. Second, because monitoring randomly restricts the financier's choice of incentive contracts, the optimal response can be to introduce a probation system. ${ }^{7}$ The literature on financing relationships typically models financing contracts as a sequence of short term contracts. ${ }^{8}$ Since short-run results are informative about the firm's quality, long term contracts will optimally use this signal. Hence, one

\footnotetext{
${ }^{5}$ This "hidden action" framework for studing the economic implication of relationships financing has been also studied by Aghion and Bolton (1997).

${ }^{6}$ Kaplow and Shavell (1994) also stress the importance of commitment when the problem of time inconsistency is prevalent.

${ }^{7}$ See Eeckhoudt et al. (1988) for an application to Insurance. Optimal probation in Personal Economics Literature includes Bull and Tedeshi (1989), Sadanand et al. (1989).

${ }^{8}$ Townsend (1982), Fudenberg, Holmstrom, and Milgrom (1990) and Rey and Salanie (1990) model sequences of short-term contracts in long-term relationships under asymmetric information. With short term financing, funds are only committed for one period, and the firm obtains continuation finance if and only if it has produced good short term results.
} 
can argue that implicit probationary periods are widely used in standard financial theory. The closest paper to ours is Ichino and Muehlheusser (2004) who analyze the possibility to use random tests in an employer-employee relationship to screen workers during probation. Apart from the distinct framework our contribution is threefold. First, we do not use the extreme monitoring strategies - probability zero or one- to characterize optimal monitoring, instead the optimal monitoring intensity arises as an equilibrium phenomenon. Second, since optimal monitoring relates to the share of bad entrepreneurs remaining in the subsequent period we endogenize the monitoring intensity when analyzing the financier's gain in profits. Finally, we emphasize a dynamic interaction observed in investment relationships: long-term financing is provided conditional on revelation-inducing action choices in early stages of the relationship. In other words, in our paper, the optimal monitoring intensity during probation serves both as a screening and discipline device that is beneficial to the financier in subsequent stages.

Our paper is also related to the hold-up literature begun by Williamson (1985). ${ }^{9}$ In the standard model, a court costlessly enforces only the aspects of the contract that it can verify. Benrhardt and Nosal (2004) present a model where the court makes errors and the parties prefer to renegotiate the original contract to eliminate ex post inefficiencies. This result mirrors ours as in our model less monitoring during a probation period promotes optimal ex ante behavior. However, in our paper, filtering out bad types of entrepreneurs through monitoring during probation is possible (or has low cost) precisely in the sense that there is no need to verify misbehavior in court in order to end the relationship.

The remainder of the paper is organized as follows. Section 2 presents the economic model. Section 3 analyzes the equilibrium behaviors of agents. Section 4 presents the gains from monitoring at random for the investor. Section 5 concludes.

\section{Model}

\subsection{Overview}

We consider a financing relationship that is assumed to last at most two periods. At date 0, a single risk-neutral entrepreneur requires external funding of one unit

\footnotetext{
${ }^{9}$ For a survey of the literature on incomplete contracts and the hold-up problem see Schmitz (2001).
} 
of capital to finance an ex ante positive NPV project. The potentially two-periodlived project is financed by a risk-neutral investor. At date 1, the entrepreneur chooses whether or not to invest in a good project. The entrepreneur's type and investment choice affect expected period project revenues. The investor does not know whether the firm should be liquidated or the entrepreneur should retain control and continue operate the firm in the second period. Thus, each manager is monitored with probability $\lambda$. At date 2, given the outcome of the monitoring procedure, the investor may immediately liquidate the firm or allow it to continue its operations. At date 2, if there is no liquidation, final payoffs are realized and period 1 ends. In period 2, all remaining entrepreneurs may receive another investment opportunity. All participants are risk neutral.

\subsubsection{Timing of events}

Period 1:

- Date 0: The investor chooses a monitoring intensity $\lambda$ for the first period.

- Date 1: Entrepreneur's investment choice $a_{i}^{\theta} \in\{G, B\}$ is made; monitoring occurs with probability $\lambda$.

- Date 2: Monitoring outcome $M \in\{G, B, 0\}$ is realized; Continuation or liquidation decision $L \in\{0,1\}$ takes place.

- Date 3: Final payoffs are realized.

\section{Period 2:}

· Entrepreneurs again make an investment choice.

\subsection{Detailed Assumptions}

\subsubsection{Entrepreneurs}

We consider $N \geq 1$ entrepreneurs, each has access to a project and seeks potential investors. Each risk-neutral entrepreneur requires one unit of capital to finance the ex ante positive NPV project. To keep the analysis simple, we assume that the relationship lasts at most two periods, $i=1,2$. The first period is a probation 
period in which the investor estimates the entrepreneur's eligibility for a long-term relationship financing. ${ }^{10}$ The second period is the time after probation.

Entrepreneurs' types are represented by a parameter $\theta \in\{h, l\}$, where "high types" are denoted by $h$ and "low types" by $l .{ }^{11}$ In the population of entrepreneurs, the proportion of high and low types is respectively $\alpha$ and $(1-\alpha)$. This information is common knowledge to all actors in the economy. ${ }^{12}$ Each entrepreneur chooses an action from $a_{i}^{\theta} \in\{G, B\}$ that corresponds to investing in a good or in a bad project in each period. The investment choice determines in turn the probability that a firm defaults. Hence, choosing a good project corresponds to taking the low-default action while choosing a bad project corresponds to taking the high default action. ${ }^{13}$ The timing of events is such that the entrepreneur learns the project type prior to take any action.

Both the entrepreneur's type, $\theta$ and his action choice, $a_{i}^{\theta}$ may affect the expected period project revenues, $y_{i}$. We assume that the revenue from a project terminated after the first period is $0 .{ }^{14}$ In the subsequent period we assume that the financier receives a high output $y_{2}>0$ from a good entrepreneur whereas a bad entrepreneur generates only $\beta y_{2}$, where $\beta<1$. $\beta$ refers to an efficiency parameter that reflects the usefulness of identifying bad entrepreneurs as early as possible. What we have in mind is that during the first period the financier monitors as well as builds a relationship with entrepreneurs. Monitoring during the initial phase of the relationship allows the investor to learn more about the entrepreneur's type and project. Yet, once the probation period has come to an end, the investor and the entrepreneur are engaged in a long term relationship in the sense that bad entrepreneurs who were not filtered out through monitoring may engage in opportunistic actions at no risk. We use $\Delta$ to capture the difference from facing a high type of entrepreneur instead of a low type. Hence, $\Delta=y_{2}-\beta y_{2}$ is the difference in expected period 2 outputs from dealing with a high type of entrepreneur rather than with a low type.

In addition, entrepreneurs are heterogeneous with respect to the costs of taking

\footnotetext{
${ }^{10}$ This assumption describes a situation in which the investor learns about the firm over time ("relationship financing").

${ }^{11}$ Our approach corresponds to a model where costs and types take a continuum of values if the distributions degenerate to a single atom (see Feldman and Winer, 2004).

${ }^{12}$ This assumption is maintained for simplicity, but could be relaxed to allow for a richer set of predictions from the model.

${ }^{13}$ Note that with a slight modification of the model, the high default action could correspond to shirking, while the low default action could correspond to work hard.

${ }^{14}$ Note that we could alternatively assume that the output from the low-default action in period 1 is $y_{1}>0$. This would not change qualitatively our results as long as we reflect the fact that the output in period 1 is negligible compared to period 2 .
} 
the low default action in each period. In particular, good entrepreneurs do not face any cost of taking the low default action. In contrast, a bad type of entrepreneur can take the costly low default action to pass himself as good and therefore avoid being liquidated at the end of the probation period. Let $c_{i}$, be the costs for bad entrepreneurs associated with taking the low default action in period $i$, where $c_{1}=c$ and $c_{2}=k . c$ with $k>0$, and $c$ is drawn from a distribution function $H(c) \in C^{2}$ with support $[0,1]$. The parameter $k$ allows for discounting costs with respect to the length of period 2 relative to period 1 .

The financing contract specifies the payment to the investor and entrepreneurial payoffs in each period. ${ }^{15}$ The expected period payment to the creditor is just the difference between expected period project revenues and expected entrepreneurial payoffs: $y_{i}-\pi_{i}$. Let $\pi_{1}$ be the entrepreneur's payoff when the project is terminated after the first period and $\pi_{2}$ is the benefit from a second period project. We assume that $\pi_{2}>\pi_{1}$. This inequality illustrates the fact that the entrepreneur benefits more the longer the relationship is continued. ${ }^{16}$ We assume furthermore that the benefit from being retained in the subsequent period outweigh the cost of effort in period 1 for a low-type entrepreneur. Alternatively, the revenue for the investor from each entrepreneur who takes a good project in period 2 is positive. Thus, it must be the case that $y_{2}>\pi_{2} \geq 1$. $^{17}$

\subsubsection{The Investor}

This subsection discusses a particular feature of the model: the investor can monitor the entrepreneur during the first stage of the relationship and the outcome of the monitoring affects the investor's decision to terminate or continue the relationship with the entrepreneur in the subsequent period. This is formalized as follows.

During period 1, the investor chooses the intensity of its monitoring activities, denoted by $\lambda \in[0,1] .{ }^{18}$ We interpret the variable, $\lambda$ to be the probability that

\footnotetext{
${ }^{15}$ To be consistent with a variety of economic environments, we impose little structure on the financing contract between the entrepreneur and the investor. In equilibrium, the investor must expect to get back at least his one unit of capital investment from the firm.

${ }^{16}$ In period 2, the entrepreneur is retained for a long-term relationship. In a more elaborate model we can imagine that the entrepreneur's reputation is enhanced if the project is not liquidated after the first period.

${ }^{17}$ In other words, the entrepreneurial payoffs in period 2 are strictly greater than the maximum cost of choosing the low default action.

${ }^{18} \mathrm{We}$ assume that the bank can commit to a monitoring intensity so that the fact that the
} 
the investor learns which action the entrepreneur chose. With probability $(1-\lambda)$, the investor will get no further information about the manager's investment choice. The outcome of the monitoring activity is defined as $M \in\{G, B, 0\}$, where $M=G$ perfectly reveals that the project is good, $M=B$ perfectly reveals that it is bad, and $M=0$ denotes the case where the entrepreneur was not monitored. It is assumed that monitoring has no cost for the investor. After observing the outcome of the monitoring activity and updating its beliefs about the entrepreneurs' types using Baye's rule, the investor makes a liquidation decision $L \in\{0,1\}$. The investor chooses to immediately liquidate the firm for a value normalized to zero, $L=1$ or allows the entrepreneur to continue operate the firm in the second period, $L=0$. It is also assumed that the population of entrepreneurs is sufficiently large such that, monitoring one entrepreneur gives no further inference about the pool of the remaining $N-1$ entrepreneurs.

We want the investor to continue rather than liquidate the project in period 2 whenever its beliefs after the monitoring process are greater or equal to the prior, $\alpha$ of dealing with a good entrepreneur. Hence, the following inequality must hold: $\alpha\left(y_{2}-\pi_{2}\right)+(1-\alpha)\left(\beta y_{2}-\pi_{2}\right)>0$. The first term corresponds to the investor's expected payoff when facing a good entrepreneur and the second term is the expected payoff from dealing with a bad entrepreneur who generates only $\beta y_{2}$.

Let us consider the investor's optimal liquidation versus continuation decision at time 2 after monitoring has been carried out. We first denote by $\epsilon \in[0,1]$ the belief of dealing with a good entrepreneur conditional on the outcome of the monitoring activity. Hence the investor's posterior belief is given by (using Baye's rule):

$$
\epsilon:=\operatorname{Pr}(\theta=h \mid M)=\frac{\alpha}{\alpha+(1-\alpha) g(\lambda)}
$$

where $g(\lambda)$ denotes the probability of investing in a good project. ${ }^{19}$

In period 2, entrepreneurial payoffs $\pi_{2}$ are paid independently of performances. Throughout we assume that both types choose the low default action when indif-

investor monitors is verifiable. To be credible the announced monitoring intensity must be incentive compatible: the financier must not have an ex post incentive to compromise commitment. For example, financiers' reputational concerns give them incentives to monitor (See Chemmanur and Fulghieri (1994) for theoretical arguments and Fang (2005) among others for empirical studies). Another possibility is to consider limited monitoring capacities (See e.g. Holmstrom and Tirole, 1997; Chiesa, 2001).

${ }^{19}$ The exact definition of this probability is given in Equation (5) below. 
ferent so that good entrepreneurs will always invest in the good project, $a_{2}^{h}=G .^{20}$ In opposition, bad entrepreneurs' payoffs are $\left(\pi_{2}-k . c\right)$ when they invest in a good project, while taking the high default action yields $\pi_{2}$. Consequently, bad entrepreneurs will always invest in a bad project, $a_{2}^{l}=B \forall c>0$. As a result, the investor's expected utility from an entrepreneur in this period as a function of $\epsilon$ is given by:

$$
\epsilon\left(y_{2}-\pi_{2}\right)+(1-\epsilon)\left(\beta y_{2}-\pi_{2}\right)
$$

Consequently, the investor will liquidate the firm whenever the outcome of the monitoring activity provides a belief sufficiently low about the entrepreneur being a good type, i.e. when:

$$
L(\epsilon)=\left\{\begin{array}{c}
1 \text { if } \epsilon<\frac{\pi_{2}-\beta y_{2}}{\Delta} \\
0 \text { otherwise }
\end{array}\right.
$$

where $\Delta=y_{2}-\beta y_{2}$ is the difference in terms of period 2 output for the investor when facing a high type of entrepreneur rather than a low type.

\section{Equilibrium Analysis}

\subsection{Entrepreneurs' Investment Choices}

The literature contains a large number of refinements of the Nash equilibrium concept. An equilibrium notion that captures the intuitions being modeled is the sequential equilibrium concept developed by Kreps and Wilson (1982). The sequential equilibrium in our environment is as follows. An entrepreneur has a choice of undertaking a good (or equivalently a low default action) or bad project (or equivalently a high default action) at date 1 . At date 2 , the investor has a choice of liquidating the firm or allowing the manager to retain control and continue operate the firm in the next period. The sequential equilibrium requires that the investor forms beliefs about the entrepreneur's type, both in the case where the entrepreneur takes the low default action and where the entrepreneur takes the high default action. Along the equilibrium path, these beliefs are formed using Baye's rule. Given the investor's beliefs and hence actions, the manager must not be able to gain from deviating.

Lemma 1 At date 1, for all $\lambda<\bar{\lambda}=\frac{1}{\pi_{2}}$, there exists a unique equilibrium continuation in which,

\footnotetext{
${ }^{20}$ All we need is that the expected payoff for the investor in period 2 from facing a good entrepreneur is positive.
} 
(i) good entrepreneurs take the low default action, while bad managers take the high default action whenever the costs of investment are sufficiently high (i.e. when $\left.\operatorname{Pr}\left(c>\lambda \pi_{2}\right)>0\right){ }^{21}$

(ii) The investor updates her beliefs about the entrepreneur's type and optimally liquidates the firms for which the outcome of the monitoring activity reveals that the entrepreneurs chose the high default action and keeps all others, including the firms that have not been monitored.

Consider first a good entrepreneur. On the equilibrium path, by taking the low default action the good entrepreneur's payoff is $\pi_{1}$ in period 1 , and $\pi_{2}$ in period 2 . If the investor monitors the entrepreneur, the outcome of the monitoring activity reveals that the project is good, i.e. $M=G$. Hence, the investor holds the beliefs $\epsilon^{*}>\alpha$. Given these beliefs, the investor optimally decides that the entrepreneur should retain control and continue to operate the firm in the second period. ${ }^{22}$ Now, if a good entrepreneur chooses the high default action, payoffs are still $\pi_{1}$ in the first period. Yet, if the entrepreneur is monitored during the probation period, with probability $\lambda$ the investor concludes that the project is bad, and the investor holds the belief $\epsilon^{*}=\operatorname{Pr}(\theta=h \mid M=B)=0$. Hence, the outcome of the monitoring perfectly reveals that the project is bad and the investor optimally liquidates the project. It follows that second period expected entrepreneurial payoffs are equal to $(1-\lambda) \pi_{2}$. As a result, a good entrepreneur will always invest in a good project during the probation period, $a_{1}^{h *}=G$.

Let us now consider a bad entrepreneur. On the equilibrium path, when an entrepreneur takes the low default action, entrepreneurial payoffs are $\pi_{1}-c$ in period 1 , where $c$ denotes the costs associated with taking the low default action incurred by bad entrepreneurs. If there is some monitoring, the entrepreneur who invests in a good project is taken to be a good type such that the project is not liquidated. In consequence, entrepreneurial payoffs in period 2 are $\pi_{2}$, since in that period, bad entrepreneurs will then invest in a bad project in order to save on costs associated with taking the low default action. Now, when a bad entrepreneur invests in a bad project, the first period entrepreneurial payoffs are still $\pi_{1}$. Recall that by taking the high default action, the entrepreneur does not incur any cost of investing. Yet, if there is some monitoring, with probability $\lambda$ he is found to be taking the high default action. In that case, the investor holds the belief $\epsilon^{*}=\operatorname{Pr}(\theta=h \mid M=B)=0$. Given

\footnotetext{
${ }^{21}$ The exact definition of this probability is given in Equation (6) below.

${ }^{22}$ In opposition, if there is no monitoring, the investor holds the belief $\epsilon^{*}=\alpha$ and the project is not liquidated either. Or, we can alternatively assume that an agent's investment project cannot be liquidated without being monitored.
} 
this belief, the investor's optimal decision is to liquidate the project. Consequently, in period 2, the entrepreneur's expected payoff from taking the high default action is equal to $(1-\lambda) \pi_{2}$. Thus, the optimal decision of a bad entrepreneur is given by:

$$
a_{1}^{l^{*}}(\lambda, c)=\left\{\begin{array}{l}
B \text { if } c>\lambda \pi_{2} \\
G \text { if } c \leq \lambda \pi_{2}
\end{array}\right.
$$

Hence, bad entrepreneurs take the high default action whenever the investment costs are sufficiently high. The conditions for which there exists an equilibrium

continuation are tied to a threshold, $\bar{\lambda}=\frac{1}{\pi_{2}}$ that relates the benefit from a longterm financing in period 2 to the maximum cost of investing for a bad entrepreneur in period 1 which is equal to 1 . Clearly, when the benefit from investing in good project is high bad entrepreneurs have strong incentives to pass themselves as good in order to avoid being liquidated. This means that there would be no information transmission in equilibrium and this prevents the financier from learning about entrepreneurs' types. Then, we will show that it is indeed optimal for the investor to choose some monitoring intensity below the threshold, $\lambda<\bar{\lambda}$ so that both possible actions, $B$ and $G$ occur with positive probability on the equilibrium path thereby allowing information revelation and screening between types.

\subsection{Investor's optimal monitoring intensity}

We now derive the investor's optimal choice of the monitoring intensity $\lambda$ at time 1 . The investor's objective is to maximize its expected payoff.

Consider a good entrepreneur. In period 1, there are $\alpha N$ good entrepreneurs. At this period, none of them invest in a bad project and in consequence, there is no liquidation. In period 2, again none of them take the high default action and the investor gets $\left(y_{2}-\pi_{2}\right)>0$ from dealing with a good entrepreneur. Note that when the investor faces good types of entrepreneurs, the payoffs are independent of the monitoring probability, $\lambda$, which in turn neither influences the number of good entrepreneurs in each period nor the entrepreneurs' investment choice.

Consider a bad entrepreneur. In period 1, a bad entrepreneur will invest in a bad project whenever the costs of investing are sufficiently high, i.e. when $c>\lambda \pi_{2}$. Hence, from the investor's point of view, the probabilities of choosing the low default action and the high default action are given by, respectively:

$$
g(\lambda):=\operatorname{Pr}\left(c \leq \lambda \pi_{2}\right)=H\left(\lambda \pi_{2}\right) \in[0,1]
$$




$$
b(\lambda):=\operatorname{Pr}\left(c>\lambda \pi_{2}\right)=1-H\left(\lambda \pi_{2}\right) \in[0,1]
$$

Clearly we have $\frac{d g}{d \lambda} \geq 0$ and $\frac{d b}{d \lambda} \leq 0$ and $b^{\prime}(\lambda)=-g^{\prime}(\lambda)$.

Since there are $(1-\alpha) N$ low-ability entrepreneurs, the expected payoff for the investor in period 1 is given by:

$$
\begin{aligned}
& V_{1}=(1-\alpha) N[b(\lambda)+g(\lambda)]\left(-\pi_{1}\right) \\
& V_{1}=(1-\alpha) N\left(-\pi_{1}\right)
\end{aligned}
$$

From the investor's point of view, monitoring during the probation period is important to the extent that it influences the number of bad types remaining in the second period. Consequently, the monitoring intensity $\lambda$ should be set in a way that induces some entrepreneurs to take the high default action in period 1 in order to allow for the detection of bad types. Formally, the number of bad entrepreneurs remaining in period 2 is composed of entrepreneurs who invested in a good project and continue to operate the firm in the second period and entrepreneurs who chose the high default action but who were not identified through monitoring: $(1-\alpha) N[g(\lambda)+(1-\lambda) b(\lambda)]$.

Given this number, the expected payoff generated by bad entrepreneurs for the investor in period 2 is given by:

$$
V_{2}=(1-\alpha) N[g(\lambda)+(1-\lambda) b(\lambda)]\left(\beta y_{2}-\pi_{2}\right)
$$

Now, rewriting equation (8) as:

$$
V_{2}(\lambda)=(1-\alpha) N Z(\lambda)
$$

where $Z(\lambda)$ is defined as,

$$
Z(\lambda)=(1-\lambda+\lambda g(\lambda))\left(\beta y_{2}-\pi_{2}\right)
$$

so that the optimal monitoring intensity, $\lambda^{*}$ is uniquely determined by $Z(\lambda)$. 
Proposition 2 If the function $Z(\lambda)$ is $C^{1}$ and convex, such that $(H(0)-1)(H(1)-$ $\left.1+H^{\prime}(1)<0\right)$, then there exists an optimal monitoring intensity, $\left.\lambda^{*} \in\right] 0, \frac{1}{\pi_{2}}[$ which induces choosing the high default action on the equilibrium path.

Proof. See the Appendix.

Note first that $\lambda^{*}<\bar{\lambda}$ implies that the equilibrium behaviors determined by Lemma 1 are optimal and so Lemma 1 together with Proposition 2 characterize indeed the unique equilibrium. The above proposition states that the monitoring intensity $\lambda$ is optimal when an interior solution is chosen: $0<\lambda^{*}<\bar{\lambda}=\frac{1}{\pi_{2}}<1$. Choosing a relatively small monitoring intensity allows the financier to identify an entrepreneur's inclination for inefficient action. This mechanism is completely independent of the costs of monitoring for the investor. Instead, it relies on the benefit for the entrepreneur from future interaction with the investor in comparison to the cost of investing in a good project at the beginning of the relationship.

\section{Substantial gains from random monitoring}

We now consider the percentage gain in profits for the investor from choosing a monitoring intensity with probability $\lambda^{*}$. Recall that the benefits of monitoring optimally relate to the share of bad entrepreneurs remaining in period 2 such that the investor is able to filter out bad types and liquidate the projects that should be liquidated.

The project is liquidated only if the entrepreneur invests in a bad project in period 1 and is detected through monitoring. From proposition 2, the optimal monitoring intensity, $\lambda^{*}$ is an interior solution. Then, the probability that a bad entrepreneur remains in period 2 is strictly less than 1 reflecting the fact that the investor is able to filter out some of the bad entrepreneurs. In that case, the investor's gain from choosing an "interior" monitoring intensity, $\lambda^{*}$ is given by:

$$
\Delta V=(1-\alpha) N\left[\lambda^{*} b\left(\lambda^{*}\right)\right]\left(\beta y_{2}-\pi_{2}\right)>0
$$

Relative to the payoff given by equation (9), the percentage increase in profits can thus be calculated as: 


$$
\Delta V \%=\frac{\Delta V}{V_{2}\left(\frac{1}{\pi_{2}}\right)}=\lambda^{*} b\left(\lambda^{*}\right)
$$

We can further illustrate this result by calculating the optimal monitoring intensity. To do this, consider the particular case where $H\left(\lambda \pi_{2}\right)=\frac{e}{e-1}\left(1-e^{-\lambda \pi_{2}}\right)$. To simplify the algebra we pose: $\frac{e}{e-1}=\theta_{0}$ such that $H\left(\lambda \pi_{2}\right)=\left(1-e^{-\lambda \pi_{2}}\right) \theta_{0}$. Using equation (5), we get $b(\lambda)=1-H\left(\lambda \pi_{2}\right)$. We thus have the following results:

It has been shown that equation (8) can be rewritten as, $V_{2}=(1-\alpha) N[1-\lambda+$ $\lambda g(\lambda)]\left(\beta y_{2}-\pi_{2}\right)$ where

$$
\begin{aligned}
Z(\lambda) & =1-\lambda+\lambda \theta_{0}-\lambda \theta_{0} e^{-\lambda \pi_{2}} \\
& =1+\lambda\left(\theta_{0}-1\right)-\lambda \theta_{0} e^{-\lambda \pi_{2}}
\end{aligned}
$$

Taking the derivative with respect to $\lambda$ yields

$$
\begin{aligned}
Z^{\prime}(\lambda) & =\theta_{0}-1-\theta_{0} e^{-\lambda \pi_{2}}+\lambda \pi_{2} \theta_{0} e^{-\lambda \pi_{2}} \\
& =\theta_{0}-1+\left(\lambda \pi_{2} \theta_{0}-\theta_{0}\right) e^{-\lambda \pi_{2}}
\end{aligned}
$$

Taking the second derivative with respect to $\lambda$ yields

$$
Z^{\prime \prime}(\lambda)=\left(2 \theta_{0} \pi_{2}-\theta_{0} \pi_{2}^{2} \lambda\right) e^{-\lambda \pi_{2}}
$$

which is clearly a convex function. Thus, there exists a $\lambda^{*}$ such that:

$$
\begin{aligned}
Z^{\prime}(\lambda) & =0 \\
& \Longleftrightarrow \theta_{0}\left(1-\lambda \pi_{2}\right) e^{-\lambda \pi_{2}}=e^{-1}
\end{aligned}
$$

thus, $\lambda^{*}$ is a global minimum of $Z(\lambda)$.

The following table illustrates our results:

\begin{tabular}{|l|l|l|l|l|}
\hline$\lambda$ & 1 & 0.5 & 0.16 & 0.067 \\
\hline$\lambda^{*}$ & 0.5 & 0.3 & 0.09 & 0.04 \\
\hline$g(\lambda)=H\left(\lambda \pi_{2}\right)$ & 0.62 & 0.69 & 0.7 & 0.71 \\
\hline$\Delta V \%=\lambda^{*} b\left(\lambda^{*}\right)$ & $19 \%$ & $9.3 \%$ & $2.7 \%$ & $1.16 \%$ \\
\hline
\end{tabular}

As $\bar{\lambda}$ decreases reflecting that the benefit from continuation in period 2 is high for a bad entrepreneur, monitoring during probation is not a very effective device 
to filter out bad types. On the other hand, when $\bar{\lambda}$ is high reflecting that the investment costs are high compared to the benefit from continuation, the investor can use monitoring as a selection device and realizes substantial gains. However, it is never optimal to set the monitoring probability $\lambda^{*}$ above the threshold $\bar{\lambda}$. In consequence, as specified by proposition 2 , the monitoring probability is optimal when it is set to, $0<\lambda^{*}<\bar{\lambda}=\frac{1}{\pi_{2}}<1$.

In summary, using probation periods seems to be more rewarding to the investor as entrepreneurs take the high default action during this period. This happens when costs associated with taking the low default action are large with high probability and when the entrepreneur's benefit from the second period is not too high.

\section{Conclusion}

The theory presented in this paper models a dynamic principal-agent costly state verification environment in which the creditor (principal) can monitor entrepreneurs (agents) during the first stage of a financing relationship. Monitoring is motivated by the need to evaluate the agent's intrinsic type and learn about his behavior when he is no longer monitored. We show that there is an incentive for the investor to choose a relatively small monitoring intensity in order to induce some of the bad entrepreneurs to take the high default action in the probation period. This mechanism relies on the share of bad entrepreneurs remaining after the probation period. Hence, the result holds even if monitoring is costless. ${ }^{23}$ Furthermore, we show that the use of probation periods, together with some monitoring during the beginning of a financing relationship, is beneficial to the principal when agents perceive a benefit from future interaction which is not too large in comparison to the cost of choosing the low default action during probation.

The paper imposes little structure on the financing contract. The principal monitors agents randomly during the probation period and this restricts her choice of incentive contract. Yet, random monitoring during the initial phase of a longterm relationship may screen out opportunistic entrepreneurs and thus is beneficial for the creditor if terminating the relationship becomes more costly over time. Our qualitative results clearly extend to more general financing contracts. For example,

\footnotetext{
${ }^{23}$ Assuming that monitoring is costly would make the optimal intensity even lower. Besanko and Spulber (1989) show that optimal investigation probabilities are less than one by appealing to the existence of convex enforcement costs functions.
} 
qualitatively, a bank enjoying an informational advantage at the subsequent stage of a relationship can extract rents and if this is anticipated by the firm, this may have negative consequences for ex ante efficiency. Overall, the contracting problem under monitoring should be set in a way that gives the firm the right incentives for effort taking and project choice but also gives the bank the incentives to take the efficient continuation/liquidation decision. It is still the case that it is optimal to introduce some randomness in the evaluation technology if the main objective for the principal is to screen agents. This paper does not recommend that creditors should use dice to select entrepreneurs, but our analysis suggests that reducing uncertainty in evaluation technologies may not improve screening, and in fact, can have the opposite effect. 


\section{Appendix}

\section{Proof of Proposition 2:}

We want to show that there exists an optimal monitoring intensity, $0<\lambda^{*}<$ $\bar{\lambda}=\frac{1}{\pi_{2}}<1$. Recall that $\lambda^{*}$ is uniquely determined by a function $Z(\lambda)$ defined as :

$$
Z(\lambda)=(1-\lambda+\lambda g(\lambda))\left(\beta y_{2}-\pi_{2}\right)
$$

Since $Z(\lambda)$ is $C^{1}$ then $Z^{\prime}(\lambda)$ is continuous in $\left[0, \frac{1}{\pi_{2}}\right]$. Then,

$$
Z^{\prime}(\lambda)=\left(-1+g(\lambda)+\lambda g^{\prime}(\lambda)\right)\left(\beta y_{2}-\pi_{2}\right)
$$

Recall that from the investor's point of view, the probability of choosing the low default action is given by:

$$
g(\lambda):=H\left(\lambda \pi_{2}\right)
$$

Then, we get :

$$
\begin{aligned}
Z^{\prime}(0) & =(g(0)-1)\left(\beta y_{2}-\pi_{2}\right)=(H(0)-1)\left(\beta y_{2}-\pi_{2}\right) \\
Z^{\prime}\left(\frac{1}{\pi_{2}}\right) & =\left(g\left(\frac{1}{\pi_{2}}\right)-1+\frac{1}{\pi_{2}} g^{\prime}\left(\frac{1}{\pi_{2}}\right)\right)\left(\beta y_{2}-\pi_{2}\right) \\
& =\left(H(1)-1+H^{\prime}(1)\right)\left(\beta y_{2}-\pi_{2}\right)
\end{aligned}
$$

Since $Z^{\prime}(0) \times Z^{\prime}\left(\frac{1}{\pi_{2}}\right)<0$, therefore, as follows from the intermediate value theorem, there exists a $\left.\lambda^{*} \in\right] 0, \frac{1}{\pi_{2}}\left[\right.$ such that $Z^{\prime}(0)=0$. Thus, $\lambda^{*}$ is a critical point, therefore $\lambda^{*}$ is a global minimum of $Z(\lambda)$. 


\section{References}

[1] Aghion, P. \& Bolton, P. (1997). A trickle-down theory of growth and development with debt overhang. Review of Economic Studies, 64, 2, 151-62.

[2] Benabou, R. \& Tirole, J. (2002). Self-confidence and personal motivation. Quarterly Journal of Economics, 117, 871-915.

[3] Bernhardt, D, \& Nosal, E. (2004). Near-sighted justice. Journal of Finance, 59, 2655-2684.

[4] Besanko, D., \& Spulber, D.F. (1989). Antitrust enforcement under asymmetric information. Economic Journal, 99, 396, 408-425.

[5] Boot, A. (2000). Relationship banking: What do we know? Journal of Financial Intermediation, 9, 7-25.

[6] Bull, C., \& Tedeshi, P. (1989). Optimal probation for new hires. Journal of Institutional and Theoretical Economics, 145, 4, 627-642.

[7] Carletti, E. (2004). The structure of relationship lending, endogenous monitoring and loan rates. Journal of Financial Intermediation, 13, 58-86.

[8] Carrillo, J., \& Mariotti, T. (2000). Strategic ignorance as a self-disciplining device. Review of Economic Studies, 67, 3, 529-544.

[9] Chemmanur, T.J., \& Fulghieri, P. (1994). Reputation, renegotiation, and the choice between bank loans and publicly traded debt. Review of Financial Studies 7 (3), 475-506.

[10] Chiesa, G. (2001). Incentive-based lending capacity, competition, and regulation in banking. Journal of Financial Intermediation, 10, 28-53.

[11] Cowen, T., \& Glazer A. (1996). More monitoring induces less effort. Journal of Economics Behavior \& Organization 30, 113-123.

[12] Cremer, J. (1995). Arm's lengh relationships. Quarterly Journal of Economics, 110, 275-295.

[13] Dewatripont, M.,\& Maskin, E. (1995). Credit and efficiency in centralized and decentralized economies. Review of Economics Studies, 62, 4, 541-555.

[14] Diamond, D.W. (1984). Financial intermediation and delegated monitoring. Review of Economic Studies, 51, 393-414. 
[15] Dubey, P., \& Wu, C. (2001). Competitive prizes: when less scrutiny induces more effort. Journal of Mathematical Economics 36, 311-336.

[16] Eeckhoudt, L., Outreville, J.F., Lauwers, M., \& Calcoen, F. (1988). The impact of probationary period on the demand for insurance. Journal of Risk and Insurance, 55, 2, 217-228.

[17] Fama, E. F. (1985). What's different about banks? Journal of Monetary Economics, 15, no.1, 29-39.

[18] Fang, L.(2005). Investment bank reputation and the price and quality of underwriting services. Journal of Finance, 60, 6, 2729-2761

[19] Feldman, D., \& Winer, R. (2004). Separating signaling equilibria under random relations between costs and attributes: Continuum of attributes. Mathematical Social Sciences, 48, 81-91, 2004.

[20] Fudenberg, D., Holmstrom, B., \& Milgrom, P. (1990). Short term contracts and long term agency relationships. Journal of Economic Theory, 51, 1-31.

[21] Fudenberg, D. \& Tirole, J. (1995). A theory of income and dividend smoothing based on incumbency rents. Journal of Political Economy, 103, 75-93.

[22] Gale, D. \& Hellwig, M. (1985). Incentive-compatible debt contracts: The one period problem. Review of Economic Studies, 52, 647-663.

[23] Hart, O., \& Holmstrom, B. (1987). The theory of contracts.In T. Bewley (ed.), Advances in Economic Theory. Cambridge: Cambridge University Press.

[24] Holmstrom, B. \& Tirole, J. (1997). Financial intermediation, loanable funds, and the real sector. Quarterly Journal of Economics, 112, 663-691.

[25] Ichino, A., \& Muehlheusser, G. (2004). How often should you open the door? Optimal monitoring to screen heterogeneous agents. mimeo.

[26] Kaplow, L., \& Shavell, S. (1994). Optimal law enforcement with self-reporting of Behavior. Journal of Political Economy, 102, 3, 583-606.

[27] Kreps, D., \& Wilson, R. (1982). Sequential equilibrium. Econometrica 50, 863894.

[28] Rey, P., \& Salanie, B. (1990). Long-term, short term and renegotiation: On the value of commitment in contracting, Econometrica, 58, 797-619. 
[29] Sadanand, A., Sadanand, V., \& Marks, D. (1989). Probationary contracts in agencies with bilateral asymmetric information, Canadian Journal of Economics, 22, 3, 643-661.

[30] Schmitz, P. (2001). The Hold-up Problem and Incomplete Contracts: A Survey of Recent Topics in Contract Theory, Bulletin of Economic Research, Blackwell Publishing, 53, 1, 1-17.

[31] Townsend, R.M. (1979). Optimal Contracts and Competitive Markets with Costly State VerificationJournal of Economic Theory, October, 265-293.

[32] Townsend, R.M. (1982). Optimal multiperiod contracts and the gain from enduring relationships under private information, Journal of Political Economy, 90, 1166-1186.

[33] Williamson, O. (1985). The Economic Institutions of Capitalism, (The Free Press, NY).

[34] Winton, A. (1993). Limitation of liability and the ownership structure of the firm, Journal of Finance, 48, 487-512. 